\title{
ANALISIS STRUKTUR BATIN SYAIR ADAT PADA MASYARAKA SIKKA KROWE DALAM TRADISI POTO WUA TA'A DI KABUPATEN SIKKA NUSA TENGGARA TIMUR
}

\section{(INNER STRUCTURAL ANALYSIS TO THE LYRIC OF TRADITIONAL POETRY OF POTO WUA TA'A OF SIKKA KROWE PEOPLE IN SIKKA DISTRICT OF NUSA TENGGARA TIMUR)}

\author{
Gisela Nuwa, Ahmad Yani \\ IKIP Muhammadiyah Maumere \\ Email: ikipmuhammadiyah_mof@yahoo.com.Email: gustavnuwa123@gmail.com
}

Diterima: 2 Mei 2019; Direvisi: 27 Mei 2019; Disetujui: 18 Juni 2019

\begin{abstract}
Abstrak
Dampak langsung dari globalisasi adalah tergerusnya bahasa, seni, serta adat-istiadat yang selama ini dijaga dan dilestarikan oleh nenek moyang, akan hilang dan tidak dikenali lagi oleh para pemuda yang hidup di zaman sekarang. Padahal, sastra lisan adat istiadat justru memiliki nilai-nilai karakter yang mampu menjadi pedoman dalam hidup bermasyarakat berbangsa dan bernegara. Berhadapan dengan tradisi poto wua ta'a yang merupakan bagian dari syair adat yang belakangan eksistensinya mulai hilang oleh perkembangan globalisasi. Tujuan dari penelitian ini adalah mendeskripsikan struktur batin dalam syair adat poto wua ta'a. Pendekatan yang digunakan dalam penelitian ini adalah struktural batin karena pendekatan ini menempatkan karya sastra sebagai dasar penelitian dan memandang karya sastra sebagai dasar penelitan serta sebagai sistem maknanya yang berlapis-lapis sebagai suatu totalitas yang tak dapat dipisahkan. Metode yang digunakan dalam penelitian ini adalah metode deskriptif kualitatif yaitu menganalisis data deskriptif dengan cara memaparkan dan mendeskripsikan sesuatu yang ada. Sumber data yang diperoleh dari narasumber berupa syair adat poto wua ta'a. Teknik dan prosedur pengumpulan data berupa: rekam, catat, observasi, wawancara. Teknik analisis data dengan cara: terjemahan syair adat poto wua ta'a, mengklasifikasi data, menganalisis data dan menyimpulkan. Berdasarkan hasil analisis, dapat disimpulkan sebagai berikut. Pertama, tema dalam syair adat poto wua ta'a adalah (1) tema perkenalan, (2) tema peminangan (3) tema keluarga, (4) tema keTuhanan. Kedua, Nada dalam syair adat Poto wua ta'a adalah (1) nada romantik yang mencakup nada tanya, nada menjawab, nada mengajak, (2) nada mencekam, (3) nada intensi/memohon, (4) nada memiliki. Ketiga, (1) rasa gembira, (2) rasa sedih, (3) rasa malu. Keempat, amanat yang terkandung dalam syair adat poto wua ta'a sebagai berikut: (1) amanat berkaitan dengan menjaga kesucian perkawinan, (2) amanat berkaitan dengan tugas dan tanggung jawab kepala keluarga, (3) jangan lupa bersyukur kepada Tuhan, (4) harus hidup rukun dan damai dengan sesama ciptaan Tuhan.
\end{abstract}

Kata Kunci: struktur batin, syair, poto wua ta'a

\begin{abstract}
The direct impact of globalization is the erosion of language, art, and customs that have been guarded and preserved by our ancestors, will be lost and no longer recognized by young people living today. Even though oral literature of customs has character values that are able to become guidelines in the life of the nation and state. Facing the tradition of Poto Wua Taa is part of the traditional poetry, whose existence has begun to disappear later in the development of globalization. The purpose of this research is to describe the inner structure in the traditional
\end{abstract}


poetry of Poto Wua Taa. The approach used in this study is inner structure because this approach places literature as the basis of research and views literature as the basis of research as well as a system of meaning that is layered as an inseparable totality. The method used in this research is a descriptive qualitative method, which is analyzing descriptive data by describing something that exists. The source of the data obtained from the speakers was in the form of the traditional poetry of Poto Wua Taa. The techniques and procedures for data collection are records, record, observation, interview. Data analysis techniques are a translation of the traditional poem of Wua Ta'a, classifying data, analyzing data and concluding. Based on the results of the analysis, it can be concluded as follows. First, the themes in the traditional poem of Wua Ta'a are (1) the theme of introduction, (2) the theme of specialization (3) the theme of the family, (4) the theme of deity. Second, tones in the Poto wua ta'a traditional poetry are (1) romantic tones which include (a) questioning tone, tone of the answer, tone inviting, (2) gripping tone, (3) tone of intention/pleading, (4) tone of possession. Third, (1) feeling happy, (2) feeling sad, (3) shame. Fourth, mandates contained in the traditional poetry of poto wua ta'a are as follows: (1) the mandate is related to maintaining the sanctity of marriage, (2) the mandate relating to the duties and responsibilities of the head of the family, (3) do not forget to thank God, (4) must live in harmony and peace with fellow creatures of God.

Keywords: inner structure, lyric, poto wua ta'a

\section{Pendahuluan}

Sastra klasik atau biasa disebut pula sebagai sastra lama atau sastra tradisional adalah karya sastra yang tercipta dan berkembang sebelum masuknya unsurunsur modernisme ke dalam sastra itu (Kosasih, 2008:19). Sastra lama memiliki banyak hubungan dengan kehidupan kita masa kini. Sastra lama merupakan kekayaan kebudayaan bangsa.

Sastra Indonesia tumbuh dan berkembang dari budaya Indonesia yang beraneka ragam. Perkembangan globalisasi dan peradaban manusia yang berkembang bersamanya sudah lama menjadi persoalan dan dibincangkan dalam pembelajaran bersastra. Globalisasi menyebabkan berbagai implikasi sehingga berbagai bidang kehidupan: ekonomi, budaya, politik, dan teknologi (terutama teknologi informasi) mengalami perubahan pesat dan inovasi yang ditimbulkannya menjadikan persoalan lokal dan internasional seakan bersifat paradoks. Oleh karena itu, keberadaan sastra di Indonesia pun beraneka ragam, mulai keragaman genre, gaya ungkap, tokoh, mitologi, hingga ke masalah sosial, politik, dan budaya etnik. Genre sastra di Indonesia tidak hanya yang tampak general, seperti prosa, puisi, dan drama, tetapi juga yang spesifik, seperti dongeng, legenda, mitos, epos, tambo, hikayat, syair, pantun, gurindam, macapat, karungut, mamanda, dan geguritan. Keberagaman genre sastra tersebut juga menyebabkan keberagaman dalam hal gaya ungkap, tokoh yang ditampilkan, semangat mitologi yang mendasari, serta masalah 
sosial, politik, dan budaya etnik dari sastrawan daerah yang menuliskan karya tersebut.

Implikasi lain dari globalisasi adalah tergerusnya bahasa, seni, serta adat-istiadat yang selama ini dijaga dan dilestarikan oleh nenek moyang akan hilang dan tidak dikenali lagi oleh para pemuda yang hidup di zaman sekarang. Padahal, sastra lisan adat istiadat justru memiliki nilai-nilai karakter yang mampu menjadi pedoman dalam hidup bermasyarakat berbangsa dan bernegara.

Satu diantara bentuk sastra yang tidak bisa dilewatkan ketika berbicara tentang khazanah sastra klasik adalah folklor (Kosasih, 2008:19). Menurut Djamaris dalam (Kosasih, 2008:19), folklor adalah kebudayaan rakyat yang disampaikan secara turun temurun, sesuatu yang mentradisi. Sastra lama mempunyai nuansa kebudayaan yang kental dan memiliki corak yang lekat dengan nilai dan adat istiadat yang berlaku di dalam suatu daerah atau masyarakat tertentu.

Syair mempunyai sifat mendidik, keagamaan, mistis, dan bersifat moral (Soetarno, 1967:28). Syair diturunkan dari mulut ke mulut dari satu generasi ke generasi berikutnya yang berisi ajaran moral, tradisi, dan pedoman hidup. Lebih lanjut dikatakan bahwa syair lisan adalah ungkapan jiwa dalam wujud bahasa secara langsung melalui percakapan (Mulyadi,
1994:1). Dengan berkaca pada kebudayaan yang ada di Kabupaten Sikka, terdapat beberapa syair lisan yang dipakai masyarakat setempat untuk menyampaikan ungkapan jiwa, dalam urusan Dua Moan Watu Pitu (sebutan lembaga pemangku adat), upacara syukuran, dan upacara peminangan. Memang, secara geografis, Kabupaten Sikka memiliki lima etnis (ata Krowe, ata Krowin, ata Lio, ata Palue, ata goan) yang masing-masingnya mempunyai gaya sastra lisan yang berbeda-beda. Meskipun demikian, secara kuantitas, syair masih didominasi oleh syair etnis ata Krowe. Etnis ini memiliki popoulasi terbanyak di kabupaten Sikka. Syair sangat memengaruhi keberlangsungan kearifan lokalnya, terutama tradisi tentang pertunangan (poto wua ta'a). Sebagaimana apa yang disampaikan oleh Mulyadi (1994), secara bersamaan, dalam tradisi Sikka Krowe untuk upacara pertunangan, terdapat juga syair lisan sebagai bentuk ungkapan jiwa dalam wujud bahasa secara langsung melalui percakapan.

Pembahasan tentang struktur batin puisi dalam kajian puisi itu sendiri sudah sangat banyak dilakukan, tetapi dalam hubungan dengan penelitian struktur batin syair adat masih sangat sedikit dilakukan. Dalam konteks tradisi Sikka, syair-syair adatnya belum pernah dikupas dan bahkan belum ada yang melakukan riset secara mendalam. Atas dasar inilah, analisis 
struktur batin dalam syair adat masyarakat Sikka Krowe dalam ritus Poto Wua Ta'a menjadi sesuatu yang khas dan berbeda dengan kajian-kajian lain dari struktur batin puisi.

Atas dasar kenyataan yang dipaparkan di atas, peneliti merasa perlu untuk melakukan penelitian "Analisis Struktur Batin dalam Syair Adat pada Masyarakat Sikka Krowe dalam ritus Poto Wua Ta'a di Kabupaten Sikka Nusa Tenggara Timur". Sastra lisan yang dimaksudkan di sini adalah syair yang dipakai dalam urusan menyampaikan perasaan seorang pria dalam meminang perempuan. Kajian ini perlu dilakukan dengan tujuan untuk melestarikan kembali budaya adat poto wua ta'a pada masyarakat Sikka Krowe di Kabupaten Sikka. Selain itu, ritus poto wua ta'a merupakan suatu wujud penjagaan moral yang harus dipatuhi dan dipertahankan oleh generasi muda.

\section{Kerangka Teori}

Salah satu ahli dalam struktualisme dinamik adalah Mukarovsky dan Felik Vodicka yang berpendapat bahwa karya sastra merupakan proses komunikasi, fakta semiotik, struktur, dan nilai-nilai (Ratna, 2011:93). Proses komunikasi berkaitan dengan aspek sosial di masyarakat. Keterkaitan antara fungsi estetika dan aspek sosial memiliki sifat yang dinamik, variabel, dan tidak tetap. Pendapat Mukarovsky ini didukung oleh Felik Vodicka yang berpendapat bahwa ilmu sastra memiliki hubungan langsung terhadap konteks sosial budaya, namun tidak bersifat searah (Teeuw, 2012:148). Dengan demikian, struktur intrinsik tetap menjadi fokus utama yang memiliki hubungan timbal balik dengan aspek sosio-kultural masyarakat.

Teori lain yang digunakan dalam mengkaji syair ini adalah teori semiotika Pierce. Pierce dalam (Ratna, 2013:101) menyebutkan ada tiga konsep triadik, yaitu (1) sintaksis semiotika; intensitas hubungan tanda dan tanda (2) semantik semiotika; fokus terhadap tanda dan acuannya, (3) pragmatik semiotika; hubungan antara pengirim dan penerima. Tanda-tanda dalam teori Pierce dihubungkan satu sama lain sehingga menimbulkan makna yang dimaksudkan. Tanda diinterpretasikan sesuai acuan yang dihubungkan dengan sosiokultural di masyarakat.

Struktualisme dinamik digunakan karena bentuk syair adat masyarakat Sikka dipengaruhi oleh aspek luar berupa budaya dan filosofis religiusitas masyarakat Sikka itu sendiri. Teori ini memudahkan dalam menganalisa bentuk syair adat poto wua ta' $a$ yang berbeda dari syair lainnya. Teori Semiotika bertujuan mengenali makna syair adat masyarakat Sikka berdasarkan tandatanda yang menyertainya. 
Terhadap teori struktualisme di atas, dalam konteks struktur batin syair adat poto wua ta'a masyarakat Sikka, dapat dipahami melalu teori struktur batin puisi. Komponen-komponen penting di dalam sebuah puisi terdapat pada unsur struktur batin puisi, yaitu: tema, nada, perasaan, dan amanat. Dalam teori L.A. Richard yang dikutip oleh Pradopo (2009:6--7), terdapat empat unsur struktur batin puisi. Penjelasannya sebagai berikut.

a. Tema adalah gagasan pokok yang dikemukakan penyair lewat puisinya. Tema puisinya biasanya mengungkapkan persoalan manusia yang bersifat hakiki, seperti cinta kasih, ketakutan, kebahagiaan, kedukaan, kesengsaraan hidup, keadilan, kebenaran, ketuhanan, kritik sosial, dan protes.

b. Nada adalah sikap penyair terhadap pokok persoalan (feeling) dan sikap penyair terhadap pembaca (tone). Nada sering dikaitkan dengan suasana.

c. Perasaan adalah rasa penyair yang diungkapkan dalam puisi. Puisi biasanya mengungkapkan perasaan gembira, sedih, cinta, dendam, dan sebagainya. Perasaan yang diungkapkan penyair bersifat total, tidak setangahsetengah.

d. Amanat merupakan pesan atau imbauan yang disampaikan penyair kepada pembaca. Amanat sebuah puisi ditafsirkan secara individual dari setiap pembaca. Pembaca yang satu mungkin menafsirkan amanat sebuah puisi berbeda dengan pembaca lain. Tafsiran pembaca mengenai amanat sebuah puisi bergantung pada sikap pembaca itu terhadap tema yang dikemukakan penyair.

Adapun secara lebih detail, unsurunsur puisi bisa dibedakan menjadi dua struktur, yaitu struktur batin dan struktur fisik. Struktur batin puisi sering pula disebut hakikat puisi. Puisi akan dapat dipahami dengan memahami sifat seni atau fungsi seni puisi, kepadatan puisi, dan ekspresi puisi.

Sejalan dengan pendapat Waluyo (1995:102), Fauziah (2016:13), mengatakan bahwa struktur batin puisi mengungkapkan apa yang hendak dikemukakan oleh penyair dengan perasaan dan suasana jiwanya. Struktur batin puisi yang dikutip oleh Fauziah sebagai berikut.

a. Tema/Makna (Sense)

Media puisi adalah bahasa. Tataran bahasa dalam puisi adalah hubungan tanda dengan makna. Maka, puisi harus bermakna, baik makna tiap kata, baris, bait maupun makna keseluruhan. Waluyo (1995:106) mengatakan "Tema merupakan gagasan pokok atau subjek-matter yang dikemukakan 
oleh penyair. Tema puisi bersifat lugas, objektif, dan khusus. Tema puisi harus dihubungkan dengan penyairnya, dengan konsep-konsep terimajinasikan".

b. Rasa (Feeling)

Rasa yaitu sikap penyair terhadap pokok permasalahan yang terdapat dalam puisinya. Pengungkapan tema dan rasa erat kaitannya dengan latar belakang sosial dan psikologi penyair, misalnya latar belakang pendidikan, agama, jenis kelamin, kelas sosial, kedudukan dalam masyarakat, usia, pengalaman sosiologis dan psikologis, dan pengetahuan.

c. Nada (Tone)

Nada yaitu sikap penyair terhadap pembacanya. Nada juga berhubungan dengan tema dan rasa. Penyair dapat menyampaikan tema dengan nada menggurui, mendikte, bekerja sama dengan pembaca untuk memecahkan masalah, menyerahkan masalah begitu saja kepada pembaca, dengan nada sombong, menganggap bodoh dan rendah pembaca, dan lainlain.

Waluyo (1995:125) mengatakan bahwa nada adalah sikap penyair kepada pembaca. Jika nada adalah sikap penyair kepada pembaca, suasana adalah keadaan jiwa pembaca setelah membaca puisi itu atau akibat psikologis yang ditimbulkan puisi itu terhadap pembaca.

d. Amanat/Tujuan/Maksud (Intention)

Seorang penyair tentu memiliki tujuan yang mendorongnya menciptakan puisi. Tujuan tersebut biasanya dicari sebelum penyair menciptakan puisi atau dapat ditemui dalam puisinya. Waluyo (1995:134) mengatakan bahwa amanat puisi adalah maksud yang hendak disampaikan atau imbauan atau pesan atau tujuan yang hendak disampaikan penyair.

Berdasarkan pemaparan di atas, batin atau hakikat puisi terbagi atas empat struktur, yaitu tema, nada, perasaan, dan amanat. Dalam penyampaiannya pun, terdapat persamaan, tidak ada perbedaan.

Di samping itu, puisi dapat dilihat dari aspek maknanya. Palmer (1976) yang dikutip oleh Pradopo (2009:6--7) mengungkapkan bahwa aspek makna yang dapat dipertimbangkan dalam puisi yaitu pengertian (sense), perasaan (feeling), nada (tone), dan tujuan (intension). Penjelasanya sebagai berikut. a. Pengertian (Sense)

Aspek ini dapat dicapai apabila antara pembicara/penulis dan kawan bicara berbahasa sama. Makna pengertian 
disebut juga tema yang melibatkan ide atau pesan yang dimaksud.

b. Perasaan (Feeling)

Aspek makna perasaaan berhubungan dengan sikap pembicara dengan situasi pembicara.

c. Nada (Tone)

Aspek makna nada (tone) adalah sikap pembicara terhadap kawan bicara atau dikatakan pula sikap penyair atau penulis terhadap pembaca.

\section{d. Tujuan (Intension)}

Aspek makna tujuan ini adalah tujuan atau maksud, baik disadari maupun tidak, akibat usaha dari peningkatan.

Berdasarkan uraian di atas, aspek makna sebuah puisi dapat dilihat dari sense, feeling, tone, dan intention sehingga makna yang terdapat di dalam puisi akan terasa oleh pembaca. Dari segi bahasa yang terkandung dalam puisi, bahasa akan menentukan sebuah makna puisi, baik dalam pengertian, perasaan, nada, dan tujuan.

Dengan demikian, dapat disimpulkan bahwa struktur batin puisi merupakan wujud kesatuan makna puisi yang terdiri atas pokok pikiran, tema, perasaan, nada, dan amanat. Tema adalah gagasan pokok yang dikemukakan penyair lewat puisinya. Nada dikaitkan dengan suasana. Nada berarti sikap penyair terhadap pokok persoalan dan sikap terhadap pembaca yang ditangkap pancaindera. Perasaan ialah pengungkapan penyair yang bersifat total, tidak setengah-setengah, memiliki fungsi simbolik, emotif dan efektif. Amanat atau pesan yang disampaikan penyair kepada pembaca merupakan pembanding dengan simpulan tentang nilai atau kegunaan puisi bagi pembaca (Djojosuroto, 2005:23--27).

\section{Metode Penelitian}

Metode yang digunakan adalah metode deskriptif kualitatif yang berusaha menggambarkan dan melukiskan data yang ada dan kemudian menarik simpulan secara umum berdasarkan masalah yang ditetapkan. Kegunaan dari metode ini adalah untuk menganalisis data deskriptif dengan cara memaparkan dan mendeskripsikan sesuatu yang ada. Nazir (1985:63) berpendapat bahwa metode deskriptif adalah suatu metode dalam meneliti status kelompok manusia, objek, kondisi, sistem pemikiran adat atau suatu kelas peristiwa pada masa sekarang. Tujuan dari penelitian deskriptif adalah untuk mendapatkan gambaran atau lukisan yang diselidiki secara sistematis, faktual, dan akurat serta untuk mengetahui hubungan antara fenomena yang diselidiki.

Sumber data dalam penelitian ini adalah syair lisan poto wua ta'a. Penyair syair ini adalah ketua adat pada etnis Krowe masyarakat Sikka. Narasumber 
tersebut sebagai informan ahli syair adat poto wua ta'a. Informan ini dipilih berdasarkan syarat-syarat informan yang dikemukakan Samarin (1988:55--57), yaitu: penutur asli tua-tua adat; pria berumur sekitar 50--60 tahun; sekurang-kurangnya berpendidikan SD; tidak terlalu lama meninggalkan daerah; tidak cacat wicara, seperti gagap; tidak terlalu lama menggunakan bahasa lain secara terus menerus; mempunyai kesehatan yang baik; bersedia menjadi informan; dan mempunyai banyak waktu untuk penelitian.

Penelitian ini menggunakan metode wawancara dengan teknik rekam dan catat. Dengan teknik ini, peneliti merekam tuturan syair adat yang dituturkan oleh tokoh-tokoh adat terpilih. Menurut Endraswara (2013:154), perekaman sastra lisan biasanya melekat pada tradisi lisan. Peneliti merekam tuturan lisan tokoh adat dengan menggunakan hand phone. Di samping itu, peneliti mencatat istilah-istilah khusus serta artinya yang dituturkan oleh informan adat terpilih saat proses perekaman berlangsung. Peneliti mencatat kata-kata sulit dengan menggunakan pena pada buku harian.

Di samping menggunakan metode wawancara, peneliti juga melakukan observasi, yaitu peneliti secara langsung mendengar atau mengamati objek penelitian. Hal ini untuk memperoleh bukti-bukti seperti yang diungkapkan dalam tuturan syair adat dan perlengkapan upacara.

Teknik yang digunakan untuk mengolah data dalam penelitian ini adalah sebagai berikut.

\section{Tanskripsi}

Setelah direkam, tuturan syair adat selanjutnya ditulis sesuai dengan aslinya (bahasa Sikka). Selanjutnya diterjemakan ke dalam bahasa Indonesia.

2. Klasifikasi data

Mengklasifikasikan data yang sudah ditranskripsikan.

3. Menganalisis data

Data yang sudah diklasifikasi selanjutnya dianalisis berdasarkan masalah yang akan dikaji. Setelah data dianalisis, dibuat simpulan akhir.

4. Membuat simpulan

Langkah terakhir adalah membuat simpulan dari data yang sudah dianalisis.

\section{Pembahasan}

\subsection{Tema Peminangan}

Kata "peminangan" berasal dari kata "pinang". Peminangan adalah upaya ke arah terjadinya perjodohan antara pria dan wanita. Meminang disebut juga melamar. Menurut etimologi, meminang atau melamar artinya meminta wanita untuk dijadikan istri (bagi diri sendiri atau orang lain). Menurut terminologi, peminangan 
ialah upaya ke arah terjadinya hubungan perjodohan antara seorang pria dengan seorang wanita atau seorang laki-laki meminta kepada seorang perempuan untuk menjadi istrinya dengan cara-cara yang umum berlaku di tengah-tengah masyarakat (Tihami, 2010:24).

Pinang dalam (KBBI, 2006:480) berarti tumbuhan yang pohonnya tidak bercabang, daunnnya berumbai-rumbai, buahnya dipakai untuk teman makan sirih. Pinang jika ditambah imbuhan awalan $p e-$ dan akhiran -an, akan mendapat sengau $M$. Maka, kata pinang akan menjadi peminangan. Dalam (KBBI, 2006:480), peminang merupakan orang atau pihak yang melamar seorang wanita untuk dijadikan istri. Pada tahap peminangan, keluarga laki-laki datang menyampaikan curahan perasaan cinta terhadap seorang perempuan yang dicintai. Jika ada respon positif dari pihak keluarga perempuan, barulah mereka membuat kesepakatan untuk memenuhi beberapa persyaratan dalam acara peminangan. Di bawah ini, penulis tampilkan data syair adat poto wua ta'a yang berkaitan dengan tema peminangan.

(9) Wua mai poto lepo Pinang datang masuk rumah Ta'a mai dokang woga Sirih datang masuk ke rumah

(10) Poto wali suku wutun Serahkan di dalam kamar
Dokang wali rabi ona

Serahkan di sudut kamar

(11) Mai litin beli lepo

Datang dan tinggallah di rumah

Bawo ler beli woga

Jadi tumpuan untuk keluarga

(12) Lepo a'un naha giit

Bangun rumah tangga kuat

Woga a'un naha mangan

Jadilah rumah tangga yang kokoh

(13) lepo au'n giit dadin

Rumah tanggah yang kuat

Woga a'un mangan totan

Rumah tanggah kokoh sepanjang masa

(14) Wua mai mera wiwir

Makan Sirih pinang merahkan bibir

Bako mai gahu ahang

Rokok hangatkan rahang

(15) Dadi du'a nora lai

Jadilah suami dan istri

Dadi bihan nora lalan

Sehingga menuju jalan lurus

Data (9) “Wua mai poto lepo /Ta'a mai dokang woga" berarti 'bahwa pinang datang masuk rumah dan sirih datang masuk ke rumah'. Syair ini menjelaskan bahwa wua mai (pinang datang) dan ta'a mai (sirih datang) itu sebenarnya adalah utusan dari pihak laki-laki. Utusan itu terdiri atas perempuan dan laki-laki. Dalam hal ini, perempuan disimbolkan dengan wua (pinang) dan laki-laki disimbolkan dengan $t a^{\prime} a$ (sirih) dan utusannya datang membawa serta sirih pinang. Dalam teorinya, Pierce (dalam Ratna, 2013:101) menyebutkan bahwa terdapat intensitas hubungan tanda dan tanda yang 
dilambangkan dengan wиa dan ta'a. Wua akan memiliki makna dalam tradisi Sikka apabila ada ta'a, wua dan ta'a merupakan dua benda yang saling memberikan makna, ibarat seorang laki-laki dan perempuan yang saling membutuhkan.

Wua ta'a (sirih pinang) merupakan alat resmi yang sangat besar nilainya di mata masyarakat. Sirih pinang merupakan alat resmi untuk menyampaikan maksud meminang perempuan. Wua ta'a merupakan pragmatik semiotika; hubungan antara pengirim dan penerima. Pengirim wua ta'a adalah laki-laki, sebagai bentuk manifestasi dirinya yang akan melamar si perempuan. Ketika perempuan melihat wua ta'a, berarti pihak perempuan dengan sendirinya paham atas niat dan tujuan dari wua ta'a yang bersangkutan.

Selanjutnya, data (10) "Poto wali suku wutun/Dokang wali rabi ona" berarti 'serahkan ke dalam kamar dan menyerahkan di sudut kamar utama'. Sirih dan pinang yang dibawa oleh utusan sang lelaki diserahterimakan dan pihak perempuan menerima dan meletakkan di kamar utama. Peletakan di sudut kamar utama ini sebagai simbol lamaran diterima baik oleh keluarga perempuan.

Data (14) "wua mai mera wiwir, bako mai gahu ahang" berarti 'sirih pinang merahkan bibir dan rokok sudah menghangatkan rahang'. Sirih dan pinang yang diterima oleh keluarga perempuan disuguhkan untuk keluarga sebagai simbol permohonan. Sirih dan pinang yang disuguhkan merupakan simbol permohonan kepada keluarga agar dapat direstui menjadi suami istri. Seperti, terdapat pada data (15) "dadi du'a nora lai, dadi bihan nora lalan" yang artinya 'jadilah suami istri dan berjalanlah menuju jalan lurus'. Syair ini menggambarkan bahwa sirih pinang yang sudah disuguhkan dan sudah memerahkan bibir serta rokok sudah menghangatkan rahang pertanda sudah direstui, hubungan laki-laki dan perempuan sudah sah menjadi suami dan istri. Ikatan yang sudah sah harus dijaga dengan saling menjaga ikatan pertunangan yang disimbolkan dengan adat poto wua ta'a.

Data (11) "Mai litin beli lepo /Bawo ler beli woga" berarti "datanglah dan tinggallah di rumah, jadi tulang punggung untuk keluarga'. Syair tersebut menggambarkan bahwa keluarga sudah menerima kehadiran laki-laki untuk menjadi bagian dari keluarga perempuan. Keluarga perempuan juga mengharapkan agar kehadiranya menjadi panutan dan harapan untuk keluarga.

Data (12) "Lepo aun naha giit / Woga aun naha mangan" berarti 'rumah tangga harus kuat dan rumah tangga harus kokoh'. Syair ini menjelaskan harapan keluarga kepada laki-laki yang sudah menjadi bagian keluarga perempuan agar dalam hidup berumah tangga harus menciptakan keluarga yang berselimutkan kedamaian dan 
keharmonisan sehingga rumah tangga kuat dan kokoh sepanjang masa. Pesan tersebut juga terdapat pada data (13) "Lepo 'aun giit dadin/Woga 'aun mangan totan” yang artinya 'sehingga rumah tangga kuat dan kokoh'. Syair ini menceritakan harapan orang tua perempuan agar rumah tangga damai dan membuahkan keluarga yang harmonis'.

\subsection{Nada romantik}

Menurut (KBBI, 2006:522), romantik merupakan bersifat mesra dan mengasyikkan sehingga menggambarkan suasana hati yang tenang dan menyenangkan. Sedangkan nada berkaitan dengan sikap penyair terhadap lawan bicaranya dalam puisi atau pembaca. Penyampaian suatu tema bisa disampaikan dengan nada memengaruhi (persuasif), menasihati, mendikte, menggurui, merendahkan, memuji, dan sebagainya (Adella, 2013). Dalam hal tertentu, nada merupakan tekanan suara agak tinggi dan diselingi oleh tekanan suara rendah dan perlahan. Berikut ini yang termasuk dalam bagian nada romantik, yaitu:

1) Nada bertanya

Tanya menurut Kamus Besar Bahasa Indonesia (KBBI, 2006) merupakan suatu permintaan keterangan, penjelasan, dan solusi. Kata tanya jika ditambah imbuhan awalan ber-, akan berubah menjadi bertanya. Bertanya merupakan permintaan keterangan atau penjelasan untuk memperoleh informasi. Dalam hal poto wua ta'a, bertanya merupakan permintaan keterangan atau informasi yang berkaitan dengan maksud kedatangan orang baru. Berikut ini penulis tampilkan bukti syair yang termasuk nada bertanya.

(1) Werun hai lau e

Orang baru siapa di sana

Watan hai reta e

Orang baru siapa di situ

(2) Te'a to'o kow apa

Jual emas atau apa

Dagang balik ko apa

Berdagang emas atau bukan

Data (1) "Werun hai lau e / Watan hai reta e" berarti 'orang baru siapa di sana, orang baru siapa di situ'. Syair ini menggambarkan rasa ingin tahu yang tinggi dari seorang perempuan saat melihat orang baru dari kejauhan. Dengan suasana hati yang tenang, perempuan mempunyai rasa ingin tahu, lalu melemparkan pertanyaan untuk mengetahui siapa sebenarnya yang datang dari kejauhan.

Data (2) "Te'a to'o kow apa / Dagang balik kow apa" berarti "jual emas atau apa, berdagang emas atau apa'. Syair ini masih tersirat keingintahuan yang begitu luar biasa 
dari seorang perempuan sehingga perempuan tersebut masih terus melemparkan pertanyaan lanjutan untuk orang baru yang belum dikenal.

\subsection{Rasa dalam Syair Adat Poto Wua Ta'a}

Ada dua istilah yang oleh para sastrawan sering kali disamakan dengan rasa, yaitu feeling dan emosi. Feeling adalah sikap masyarakat terhadap pokok permasalahan atau objeknya, sedangkan emosi adalah keadaan batin yang kuat, yang memperlihatkan kegembiraan, kesedihan, keharuan, atau keberanian yang bersifat subjektif. Dalam syair adat ini, secara tersirat digambarkan rasa emosional yang ditujukan kepada kedua calon mempelai dan juga para pendengar lainnya. Berdasarkan penelitian yang telah dilakukan, rasa yang terdapat dalam syair adat poto wua ta'a sebagai berikut.

(a) rasa senang, (b) rasa ibah/empati, dan

(c) rasa malu.

Penjelasan tentang rasa yang terdapat pada syair adat poto wua ta'a tersebut sebagai berikut.

1) Rasa senang

Rasa senang merupakan perasaan terbebas dari ketegangan. Biasanya, kesenangan itu disebabkan oleh hal-hal yang bersifat tiba-tiba (surprise) dan bersifat sosial, melibatkan orang-orang lain di sekitar orang yang senang (Seligman, 2005:144). Di bawah ini, peneliti tampilkan rasa senang dalam syair adat poto wua ta'a.

(11) Mai litin beli lepo

Datang dan tinggallah di rumah

Bawo ler beli woga

Jadi tumpuan untuk keluarga

(12) Lepo aun naha giit

Bangun rumah tangga kuat

Woga a'un naha mangan

Jadilah rumah tangga yang kokoh

(14) Wua mai mera wiwir Siri pinang merahkan bibir Bako mai gahu ahang Rokok sudah hangatkan rahang

(15) Dadi du'a nora lai Jadilah suami dan istri Dadi bihan nora lalan Sehingga menuju jalan lurus

Data (9) "Wua mai poto lepo/Ta'a mai dokang woga' berarti 'pinang datang masuk rumah, siri datang masuk ke rumah'. Syair ini secara tersirat menggambarkan rasa senang yang tergambar dalam wajah keluarga laki-laki karena kehadiran mereka disambut baik oleh keluarga perempuan.

Data (10) "Poto wali suku wutun/ Dokang wali rabi ona" berarti 'serahkan di dalam kamar, 
serahkan di sudut kamar'. Data “(14) "Wua mai mera wiwir/Bako mai gahu ahang" berarti 'sirih pinang merahkan bibir, rokok sudah hangatkan rahang'. Syair di atas secara tersirat menggambarkan kebahagiaan yang tergambar dalam diri keluarga perempuan saat menerima sirih pinang dari pihak laki-laki. Sirih pinang itu lalu disuguhkan untuk keluarga yang hadir saat itu sebagai simbol permohonan agar hubungan mereka direstui.

Setelah sirih pinang dimakan oleh keluarga, keluara menyatakan bahwa sirih pinang yang dimakan sebagai pertanda hubungan mereka direstui, seperti yang terdapat pada data (15) "Dadi du'a nora lai / Dadi bihan nora lalan" yang artinya 'jadilah suami dan istri, jadilah menuju jalan lurus'. Syair ini menggambarkan kebahagiaan dalam diri laki-laki dan perempuan saat keluarga kedua belah pihak makan sirih pinang dan menyatakan bahwa anak mereka sudah disahkan menjadi suami dan istri yang kelak akan menjadi keluarga yang harmonis, selalu menjalankan kehidupan dengan jalan mulus, serta dapat memecahkan masalah keluarga sendiri.

Dalam syair di atas, terlihat jelas kesenangan keluarga perempuan saat menerima wua ta'a (siri pinang) dari keluarga laki-laki. Keluarga laki-laki juga merasa bahagia karena kedatangan mereka diterima dengan baik. Kesenangan juga terdapat dalam data (11) "Mai litin beli lepo/Bawo ler beli woga" yang artinya 'datang dan tinggallah di rumah, jadi tumpuan untuk keluarga'. Syair ini menggambarkan rasa kegembiraan dan rasa memiliki yang sangat mendalam sehingga orang tua perempuan langsung menyambut baik kehadiran keluarga laki-laki dan langsung menyampaikan harapan mereka agar suatu saat menjadi tumpuan harapan untuk keluarga.

Data (12) "Lepo aun naha giit/Woga a'un naha mangan" berarti 'bangun rumah tangga yang kuat, jadilah rumah tangga yang kokoh'. Syair ini menggambarkan rasa gembira pihak keluarga perempuan. Mereka merasa memiliki sepenuhnya anak laki-laki tersebut. Keluarga perempuan menyampaikan harapan agar perpaduan dari dua insan menjadi 
satu dan semoga perpaduan tersebut menjadi ikatan yang kuat dan kokoh, tidak dapat dipisahkan. Mereka juga berharap agar kehadiran pengantin laki-laki menjadikan keluarga perempuan semakin kuat dan kokoh serta menjadikan rumah tangga mereka harmonis.

2) Rasa Iba

Menurut (KBBI, 2006:245), rasa iba merupakan perasaan kasihan, terharu, dan kasihan terhadap suatu peristiwa yang terjadi. Di bawah ini, ditampilkan bait syair adat poto wua ta'a yang mengandung rasa haru.

(28) Uhe mu'e du'e die Pintu selalu terbuka Dan mu'e gera hading Tangga disini menanti

(29) Bui ba'a men buan Menuggu anak kandung Nawang ba'a pun lu'ur Menanti anak mantu

(30) Nari oti wa'in Istrahat kaki dulu Plo oti nain

Tarik nafas dulu

(31) Emai ita ea daha Mari kita makan nasi Ebawo ita tinu linok Mari kita minum air

Data (28) "Uhe mu'e du'e die /Dan mu'e gera hading berarti 'pintu selalu terbuka, tangga di sini menanti'. Syair ini menggambarkan orang tua merasa iba, seperti kehilangan anak laki-laki yang harus pergi dan menjadi anggota keluarga perempuan. Orang tua menyampaikan bahwa pintu selalu terbuka lebar dan tangga rumah selalu menanti kehadiran kalian.

Data (29) “Bui ba'a men buan /Nawang ba'a pun lu'ur berarti 'menuggu anak kandung dan menanti anak mantu'. Syair ini menceritakan kasih sayang orang tua yang merasa terharu saat melepas pergi anak mereka yang akan menjadi anggota dalam keluarga perempuan. Mereka berpesan kepada anak mereka bahwa mereka selalu menantikan kehadiran anak kandung mereka dan istrinya suatu saat nanti.

Data (30) "Nari oti wa'in / Plo oti nain" berarti 'istirahatkan kaki dulu, tarik nafas dulu'. Syair ini menggambarkan rasa iba sang istri kepada suaminya yang baru pulang dari kebun. Istri menyuruh suaminya untuk mengistrahatkan kaki dan menarik napas. Syair ini merupakan bagian dari nasihat orang tua kepada anak perempuan mengenai tugas pelayanan seorang istri kepada suaminya saat pulang kerja.

Syair berikut menggambarkan rasa empati seorang istri setelah mengarahkan suaminya untuk istirahat dan makan. Hal ini terdapat pada data (31) "emai ita ea daha / ebawo ita tinu linok" yang artinya 
'mari kita makan nasi, mari kita minum air'. Syair ini menggambarkan rasa empati seorang istri kepada suaminya. Saat suami pulang kerja, seorang istri harus menyiapkan makanan untuk sang suami.

\subsection{Amanat dalam Syair Adat Poto Wu'a Ta'a}

(14) Wua mai mera wiwir Sirih pinang merahkan bibir Bako mai gahu ahang Rokok sudah hangatkan rahang

(15) Dadi du'a nora lai Jadilah suami dan istri Dadi bihan nora lalan Sehingga menuju jalan lurus

(16) Lopa gou ata roun Jangan memetik daun terlarang Lopa bata ata ubun Jangan memetik pucuk terlarang

(19) Ma gopi uma gete Pergi dan bukalah kebun besar Ma kare tua mosan Pergi dan irislah moke

Data (14) "Wua mai mera wiwir / Bako mai gahu ahang" berarti 'sirih pinang merahkan bibir, rokok sudah hangatkan rahang'. Syair ini menggambarkan orang tua yang memberikan pesan kepada perempuan sekaligus mengingatkan kembali bahwa sirih dan pinang sudah diterima dan sudah dimakan. Syair ini juga mengingatkan pasangan harus bisa membawa diri masing-masing.

Data (15) "Dadi dua nora lai / Dadi bihan nora lalan” berarti 'jadilah suami dan istri, sehingga menuju jalan lurus'. Syair ini menjelaskan orang tua yang memberikan nasihat kepada lakilaki dan perempuan. Sirih pinang sudah dimakan berarti pasangan dinyatakan sah menjadi suami dan istri.

Data (16) "Lopa gou ata roun / Lopa bata ata ubun" berarti 'jangan memetik daun terlarang, jangan memetik pucuk terlindung'. Syair tersebut menjelaskan bahwa roun dan ubun atau daun dan pucuk tersebut adalah simbol dari wanita lain atau laki-laki lain atau bisa juga merupakan harta milik orang lain. Artinya, dalam hidup berumah tangga, suami dan istri harus saling menjaga kejujuran. Jangan sampai mengambil atau merampas barang milik orang lain. Istri harus setia pada suami, jangan melirik suami orang. Sebaliknya, suami tidak boleh melirik istri orang karena hal tersebut merupakan perbuatan tidak terpuji. Dalam hal ini, tugas orang tua memberikan nasihat kepada suami dan istri agar menjauhi pantangan atau janji adat sehingga rumah tangga mereka tidak rusak.

Data (19) "Ma gopi uma gete / Ma kare tua mosan" berarti 'pergi dan bukalah kebun besar, pergi dan irislah moke'. Syair ini secara tersirat menggambarkan tanggung jawab orang tua yang begitu besar kepada anak-anak mereka yang sudah berkeluarga. Orang 
tua memberikan nasihat kepada anak laki-laki harus bekerja keras membanting tulang untuk menghidupi anak istrinya.

\section{Penutup}

Menghadapi persoalan yang terjadi dewasa ini, terutama perkembagan globalisasi dan peradaban manusia yang kian menggerogoti eksistensi bahasa, tradisi dan seni, penulis melakukan analisis pada syair adat poto wua ta'a. Syair adat poto wua ta'a. memiliki empat struktur batin. Pertama, tema yang terdapat dalam syair adat poto wua ta'a yaitu (1) tema perkenalan, (2) tema peminangan, (3) tema keluarga, dan (4) tema ketuhanan. Kedua, nada yang terdapat dalam syair adat poto wua ta'a yaitu (1) nada romantik yang mencakup (a) nada tanya, (b) nada menjawab, (c) nada mengajak, (2) nada mencekam, (3) nada intensi/ memohon, dan (4) nada memiliki. Ketiga, rasa yang terdapat dalam syair adat poto wu'a ta'a yaitu (1) rasa gembira, (2) rasa sedih, dan (3) rasa malu. Keempat, amanat yang terkandung dalam syair adat poto wua ta'a yaitu (1) amanat yang berkaitan dengan menjaga kesucian perkawinan; (2) amanat yang berkaitan dengan tugas dan tanggung jawab seorang kepala keluarga; (3) amanat jangan lupa akan doa dan permohonan kepada Tuhan; dan (4) sebagai makluk ciptaan Tuhan, kita harus peduli dan rukun damai dengan keluarga dan masyarakat.

\section{Daftar Pustaka}

Adella, Sekar Eva Latifa. (2013). Ekspresi Cinta DalamPuisi-Puisi Karya Won Tae-Yeon dan Kim Soe-Yeop. Depok: $\mathrm{UI}$

Alwi, Hasan. (2006). Kamus Besar Bahasa Indonesia. Jakarta: Departemen Pendidikan Nasional, Pusat Bahasa.

Ahsin, Muhammad Noor. dkk. (2017). "Struktur Fisik dan Struktur Batin Antologi Puisi Tentang Jejak Yang Hilang". Jurnal Pendidikan Bahasa Indonesia Universitas Muria Kudus (UMK) 5, 61--74.

Darlis. (2016). "Struktur Batin Lima Puisi Chairil Anwar". Dalam Kumpulan Puisi "Aku Ini Binatang Jalang. Jurnal Bastra (Bahasa dan Sastra) FKIP UHO 2, 1--12.

Djojosuroto, Kinayati. (2006). Analisis Teks Sastra dan Pengajarannya. Yogyakarta: Pustaka.

Endraswara, Suwardi. (2003). Metodologi Penelitian Sastra.Yogyakarta: Pustaka Wijaya.

Kosasih. (2008). Khazanah Sastra Melayu Klasik. Jakarta: Nobel Edumedia.

Mulyadi. (1994). Penelitian Sastra Melayu Tradisional dalam Dasawarsa Terakhir di Indonesia: Sebuah Tinjauan dalam Analisis Kebudayaan. Jakarta: Departemen Pendidikan dan Kebudayaan.

Nazir, Muhamad. (1985). Metodologi penelitian. Jakarta: Galian Indonesia.

Parera, Mandalangi. (1998). Kamus Sara Sikka Bahasa Indonesia. Manuskrip.

Pareira, Edmundus. (1991). Seputar Warisan Adat Sikka. Maumere: Pustaka Ledalero. 
Pradopo, Rachmat Djoko. (2009). Beberapa Teori Sastra, Metode Kritik, dan Penerapannya. Yogyakarta: Pustaka Pelajar.

Ratna, Nyoman Kutha. (2013). Teori, Metode, dan Teknik Penelitian Sastra. Yogyakarta: Pustaka Pelajar.

Tim Penyusun. (2016). "Panduan Penelitian dan Penulisan Skripsi”. Maumere: IKIP Muhammadiyah Maumere.

Samarin, William J. (1988). Ilmu Bahasa Lapangan. Yogyakarta: Kanisius.

Soetarno. (1967). Peristiwa Sastra Melayu Lama. Surakarta: PT. Widya Duta Surakarta.
Seligman. (2005). Menciptakan Kebahagiaan dengan Psikologi Positif (Authentic Happiness). Bandung: PT. Mizan Pustaka.

Tihami, Sohari Sahrani. (2010). Fikih Munakahat. Jakarta: Raja Grafindo Persada.

Tim Prima Pena. (2003). Kamus Besar Bahasa Indonesia. Jakarta: gramedia Press.

Teeuw, A. (2012). Sastra dan Ilmu sastra. Jakarta: Dunia Pustaka Jaya.

Waluyo, Herman J. (1995). Teori dan Apresiasi Puisi. Jakarta: Erlangga. 